\title{
A Maximum Cut Approximation Algorithm for Tracheostomy
}

\author{
Nedev Roumen* \\ Ingeniería en Tecnologías de la Información, México \\ *Corresponding author: Nedev Roumen, Ingeniería en Tecnologías de la Información, Calle de la Claridad S/N, Col \\ Plutarco Elías Calles, Mexicali, Baja California, México
}

\begin{tabular}{|c|c|}
\hline ARTICLE INFO & ABSTRACT \\
\hline Received: 萧 June 11, 2019 & In this note, is presented a computational approach for analysis of a tracheostomy \\
\hline Published: 慧 June 17, 2019 & $\begin{array}{l}\text { procedure, one which is performed in critically ill patients, and its monitoring is important, } \\
\text { since a prolonged mechanical ventilation for respiratory failure and airway issues must be }\end{array}$ \\
\hline
\end{tabular}

Citation: Nedev Roumen. A Maximum Cut Approximation Algorithm for Tra-

Keywords: Tracheostomy; MAX-CUT cheostomy. Biomed J Sci \& Tech Res 18(5)-2019. BJSTR. MS.ID.003218.

\section{Introduction}

The MAX-CUT problem is one of the basic and most prominent problems in Approximation Algorithms, due mainly to its large connection with other optimization problems and their application in different domains, such as Data Mining, Critical Resource Allocation, among others. A graph $\mathrm{G}$ with vertex set $\mathrm{V}$, and edge set $\mathrm{E}$ is given, and we want to partition it, in such a way that there should be the maximum number of edges between some set of vertices $\mathrm{S}$ and its complement $\mathrm{V}-\mathrm{S}$. Based on recent studies of randomized trail [1], it is considered necessary to wait for 10 days before a patient should be considered for mechanical ventilation. Since, complications are related to tracheostomies, such as: pneumothorax, bleeding, vocal cord dysfunction, etc., the performance of the surgery, and the selection of ill patients suitable for it, has been a relevant topic of debate.

\section{Methods}

The MAX-CUT problem is suitable for a single or multicommodity flow problem, where the underlying network has $n$ nodes set $\mathrm{V}$ and $\mathrm{m}$ edges set $\mathrm{E}$. Since each edge e is provided with a capacity flow $\mathrm{C}(\mathrm{e})$, such that a maximum nonnegative flow of $\mathrm{C}$ units can slip through the edge. Two particular nodes characterize the net, one is the source $s$ and the other the sink t. The maximum flow that can run through it, from the source to sink, in accordance with the capacity restrictions is associated with the minimum cut, that is the subset of edges that need to be removed from the network, in order to disconnect the source s from the sink t. However, an interesting approximation to build a MAX-CUT from there is based on the greedy algorithm of local improvement. Approximation algorithms for MAX-CUT are extensively studied in the literature [2], however the dynamic approach for our case is based on the sense of the capacities, based on the following indications shown in Table 1 [3-5]. The procedure is based on the following iterative cycle: Repeat Add a single node to the subset $\mathrm{S}$, until no further improvement is possible (Figure 1).

Table 1: Criteria for the selection of patients for Tracheostomy.

\begin{tabular}{|c|}
$\begin{array}{c}\text { Indications for Adding a Single Node or Removing it from the MAX- } \\
\text { CUT Construed }\end{array}$ \\
\hline Managing secretion (pulmonary hygiene) \\
\hline Ventilation weaning \\
\hline Intubation \\
\hline Upper airway obstruction \\
\hline Arterial desaturation \\
\hline Bilateral vocal cord paralysis \\
\hline Airway protection \\
\hline
\end{tabular}



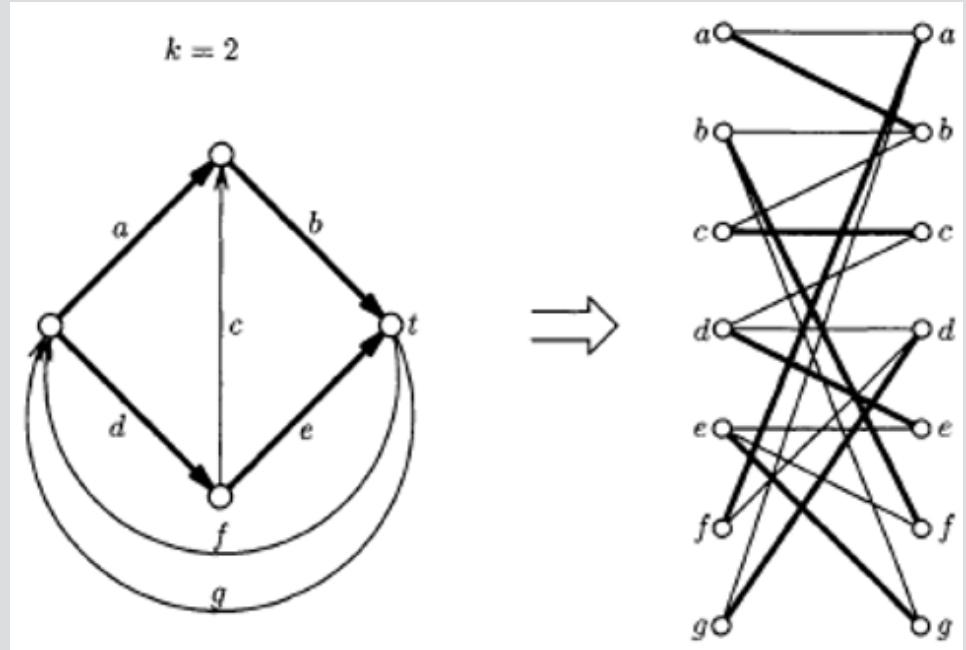

Figure 1: Heuristic approach for the local improvement of MAX-CUT.

\section{Discussion}

Any search problem can be modeled as a relation of some function to the vertices of the $\{0,1\}$-cube of $\mathrm{k}$ - dimensions. In the case when all commodities between any two given edges are equal, the MAX-CUT is obtained by the conditions on the flow of the dual graph.

\section{References}

1. Sugerman Harvey J, Wolfe Luke, Pasquale Michael D, Rogers Frederick B, O’Malley Keith F, et al. (1997) Multicenter, Randomized, Prospective Trial of Early Tracheostomy. J Trauma 43(5): 741-747.

\section{ISSN: 2574-1241}

DOI: 10.26717/BJSTR.2019.18.003218

Nedev Roumen. Biomed J Sci \& Tech Res

(c) (P) This work is licensed under Creative

Submission Link: https://biomedres.us/submit-manuscript.php
2. Papadimitriou CH (1995) Computational Complexity. Addison-Wesley Pub Co, Boston, USA, pp. 540.

3. Fu Z, Sun X, Liu Q, Zhou L, Shu J (2015) Achieving Efficient Cloud Search Services: Multi-Keyword Ranked Search over Encrypted Cloud Data Supporting Parallel Computing. IEICE Transactions on Communications 98(1): 190-200.

4. Fujimoto RM (1990) Parallel discrete event simulation. Communications of the ACM 33(10): 30-53.

5. Ghosh K, Fujimoto RM (1991) Parallel discrete event simulation using space-time memory. In Proceedings of the 1991 International Conference on Parallel Processing 3: 201-208.

$\begin{array}{ll}\text { BIOMEDICAL } & \text { Assets of Publishing with us } \\ \text { RESEARCHES } & \text { - Global archiving of articles } \\ & \text { - Immediate, unrestricted online access } \\ \end{array}$

